\title{
PENGARUH HARGA, KUALITAS PELAYANAN, DAN PROMOSI TERHADAP MINAT MASYARAKAT BERSEKOLAH DI SMAM WANARAJA
}

\author{
Ahmad Darda \\ Budiman Abdulah \\ STIE Muhammadiyah Jakarta
}

\begin{abstract}
Abstrak. Penelitian ini bermaksud untuk mengetahui, mengkaji dan menganalisi pengaruh Harga $\left(\mathrm{X}_{1}\right)$, Kualitas Pelayanan $\left(\mathrm{X}_{2}\right)$ dan Promosi $\left(\mathrm{X}_{3}\right)$ terhadap Minat Masyarakat $\left(\mathrm{X}_{4}\right)$, pada masyarakat untuk bersekolah di SMAM Wanaraja. Instrumen yang digunakan untuk menjaring data variabel minat masyarakat, harga, kualitas pelayanan dan promosi menggunakan angket penyebaran kuesioner model Skala Likert. Uji validitas dihitung dengan rumus Product Moment dan Reliabilitas dihitung dengan Alpha Cronbach. Data dianalisis dengan statistik deskripsi dan inferensial, untuk pengujian hipotesis digunakan uji korelasi dan analisis jalur. Hasil penelitian menunjukan bahwa : pertama, terdapat pengaruh langsung positif dan signifikan harga terhadap kualitas pelayanan 0.238. Kedua, terdapat pengaruh secara positif dan signifikan haraga terhadap promosi 0.375 . Ketiga, terdapat pengaruh secara positif dan signifikan harga terhadap minat masyarakat sebesar 0.303. Keempat, terdapat pengaruh secara positif dan signifikan kualitas pelayanan terhadap promosi sebesar 0.191. Kelima, terdapat pengaruh secara positif dan signifikan kualitas pelayanan terhadap minat masyarakat sebesar 0.142. Keenam, terdapat pengaruh secara positif dan signifikan promosi terhadap minat masyarakat sebesar 0.620.
\end{abstract}

Kata Kunci : Harga, Kualitas Pelayanan, Promosi, Minat Masyarakat

\section{PENDAHULUAN}

Sebuah lembaga yang ingin sukses dimasa depan, dalam menghadapi persaingan era globalisasi harus mempraktekkan marketing terus menerus agar mendapatkan jumlah siswa yang dikehendaki karena semakin meningkatnya jumlah atau calon siswa yang masuk dapat mengangkat citra positif pada sebuah lembaga dimata masyarakat. Apalagi sekarang ini menurunnya perekonomian nasional dapat berdampak memperburuk lingkungan pemasaran sehingga dapat menurunkan minat masyarakat untuk bersekolah. Minat merupakan hasil pengalaman belajar, minat tidak dibawa sejak lahir, tetapi terbentuk dari pengalaman (H.C. Witherington. 1985.135). akibat dari adanya itu, maka sebuah lembaga pendidikan harus seaktif mungkin dalam memasarkan lembaganya untuk memperoleh peserta didik. Apabila harga, kualitas pelayanan dan promosi dikelola secara professional dan sumber daya selebihnya memadai, jumlah tamatan siswa yang masuk dilembaga pendidikan pada setiap tahun ajaran baru pasti lebih besar dari tahun sebelumnya, yang artinya menunjukkan bahwa lembaga pendidikan tersebut mampu memberikan kepuasan terhadap pelanggan.

Semakin menjamurnya lembaga pendidikan khususnya di Kab. Garut, tentunya bisa dibuktikan dari data table BPS 2017 Kabupaten Garut di bawah ini.

\begin{tabular}{|c|l|c|c|c|}
\hline \multirow{2}{*}{ Kode } & \multirow{2}{*}{ Kecamatan } & \multicolumn{3}{|c|}{ SMP } \\
\cline { 3 - 5 } & & Jumlah & Negeri & Swasta \\
\hline 010 & Cisewu & 10 & 6 & 4 \\
\hline 011 & Caringin & 12 & 4 & 8 \\
\hline 020 & Talegong & 8 & 2 & 6 \\
\hline 030 & Bungbulang & 17 & 7 & 10 \\
\hline
\end{tabular}


JURNAL EKOBIS, Ekonomi Bisnis \& Manajemen

\begin{tabular}{|c|c|c|c|c|}
\hline 031 & Mekarmukti & 4 & 2 & 2 \\
\hline 040 & Pamulihan & 3 & 3 & 0 \\
\hline 050 & Pakenjeng & 18 & 9 & 9 \\
\hline 060 & Cikelet & 9 & 7 & 2 \\
\hline 070 & Pameungpeuk & 6 & 2 & 4 \\
\hline 080 & Cibalong & 7 & 7 & 0 \\
\hline 090 & Cisompet & 8 & 5 & 3 \\
\hline 100 & Peunduey & 3 & 2 & 1 \\
\hline 110 & Singajaya & 3 & 2 & 1 \\
\hline 111 & Cihurip & 2 & 2 & 0 \\
\hline 120 & Cikajang & 10 & 3 & 7 \\
\hline 130 & Banjarwangi & 7 & 4 & 3 \\
\hline 140 & Cilawu & 13 & 5 & 8 \\
\hline 150 & Bayongbong & 12 & 4 & 8 \\
\hline 151 & Cigedug & 7 & 2 & 5 \\
\hline 160 & Cisurupan & 11 & 3 & 8 \\
\hline 161 & Banyuresmi & 14 & 3 & 11 \\
\hline 161 & Sukarersmi & 4 & 1 & 3 \\
\hline 170 & Samarang & 9 & 2 & 7 \\
\hline 171 & Pasirwangi & 10 & 2 & 8 \\
\hline 181 & Tarogong Kidul & 15 & 5 & 10 \\
\hline 182 & Tarogong Kaler & 12 & 2 & 10 \\
\hline 190 & Garut Kota & 17 & 8 & 9 \\
\hline 200 & Karangpawitan & 13 & 4 & 9 \\
\hline 210 & Wanaraja & 5 & 1 & 4 \\
\hline 211 & Sucinaraja & 3 & 1 & 2 \\
\hline 212 & Pangatikan & 3 & 2 & 1 \\
\hline 220 & Sukawening & 6 & 1 & 5 \\
\hline 221 & Karangtengah & 5 & 1 & 4 \\
\hline 240 & Leles & 11 & 3 & 8 \\
\hline 250 & Leuwigoong & 3 & 2 & 1 \\
\hline 260 & Cibatu & 11 & 1 & 10 \\
\hline 261 & Kersamanah & 5 & 2 & 3 \\
\hline 270 & Cibiuk & 7 & 2 & 5 \\
\hline 280 & Kadungora & 9 & 3 & 6 \\
\hline 290 & $\begin{array}{l}\text { Bulubur } \\
\text { Limbangan }\end{array}$ & 11 & 4 & 7 \\
\hline 300 & Selaawi & 8 & 3 & 5 \\
\hline 310 & Malangbong & 13 & 5 & 8 \\
\hline \multicolumn{2}{|c|}{ TOTAL } & 364 & 139 & 225 \\
\hline
\end{tabular}

\begin{tabular}{|c|l|c|c|c|}
\hline 070 & Pameungpeuk & 3 & 1 & 2 \\
\hline 080 & Cibalong & 2 & 1 & 1 \\
\hline 090 & Cisompet & 3 & 1 & 2 \\
\hline 100 & Peunduey & 2 & 0 & 2 \\
\hline 110 & Singajaya & 3 & 1 & 2 \\
\hline 111 & Cihurip & 1 & 1 & 0 \\
\hline 120 & Cikajang & 4 & 1 & 3 \\
\hline 130 & Banjarwangi & 3 & 0 & 3 \\
\hline 140 & Cilawu & 3 & 1 & 2 \\
\hline 150 & Bayongbong & 2 & 1 & 1 \\
\hline 151 & Cigedug & 4 & 0 & 4 \\
\hline 160 & Cisurupan & 3 & 2 & 1 \\
\hline 161 & Banyuresmi & 3 & 1 & 2 \\
\hline 161 & Sukarersmi & 3 & 0 & 3 \\
\hline 170 & Samarang & 2 & 1 & 1 \\
\hline 171 & Pasirwangi & 4 & 0 & 4 \\
\hline 181 & Tarogong Kidul & 6 & 3 & 3 \\
\hline 182 & Tarogong Kaler & 2 & 0 & 2 \\
\hline 190 & Garut Kota & 6 & 1 & 5 \\
\hline 200 & Karangpawitan & 2 & 1 & 1 \\
\hline 210 & Wanaraja & 2 & 0 & 2 \\
\hline 211 & Sucinaraja & 1 & 1 & 0 \\
\hline 212 & Pangatikan & 0 & 0 & 0 \\
\hline 220 & Sukawening & 4 & 1 & 3 \\
\hline 221 & Karangtengah & 1 & 0 & 1 \\
\hline 240 & Leles & 3 & 1 & 2 \\
\hline 250 & Leuwigoong & 1 & 1 & 0 \\
\hline 260 & Cibatu & 4 & 1 & 3 \\
\hline 261 & Kersamanah & 2 & 0 & 2 \\
\hline 270 & Cibiuk & 2 & 0 & 2 \\
\hline 280 & Kadungora & 4 & 0 & 4 \\
\hline 290 & Bulubur & 4 & 1 & 3 \\
\hline 300 & Selaawi & 0 & 0 & 0 \\
\hline 310 & Malangbong & 4 & 1 & 3 \\
\hline & TOTAL & 120 & 30 & 90 \\
\hline & & & & \\
\hline
\end{tabular}

\begin{tabular}{|c|l|c|c|c|}
\hline \multirow{2}{*}{ Kode } & \multirow{2}{*}{ Kecamatan } & \multicolumn{3}{|c|}{ SMK } \\
\cline { 3 - 5 } & & Jumlah & Negeri & Swasta \\
\hline 010 & Cisewu & 5 & 1 & 4 \\
\hline 011 & Caringin & 1 & 0 & 1 \\
\hline 020 & Talegong & 2 & 0 & 2 \\
\hline 030 & Bungbulang & 5 & 0 & 5 \\
\hline 031 & Mekarmukti & 3 & 0 & 3 \\
\hline 040 & Pamulihan & 1 & 1 & 0 \\
\hline 050 & Pakenjeng & 4 & 0 & 4 \\
\hline 060 & Cikelet & 4 & 1 & 3 \\
\hline 070 & Pameungpeuk & 4 & 0 & 4 \\
\hline 080 & Cibalong & 1 & 0 & 1 \\
\hline 090 & Cisompet & 2 & 0 & 2 \\
\hline 100 & Peunduey & 2 & 0 & 2 \\
\hline
\end{tabular}




\begin{tabular}{|c|c|c|c|c|}
\hline 110 & Singajaya & 1 & 0 & 1 \\
\hline 111 & Cihurip & 1 & 0 & 1 \\
\hline 120 & Cikajang & 3 & 0 & 3 \\
\hline 130 & Banjarwangi & 2 & 0 & 2 \\
\hline 140 & Cilawu & 7 & 1 & 6 \\
\hline 150 & Bayongbong & 8 & 1 & 7 \\
\hline 151 & Cigedug & 1 & 0 & 1 \\
\hline 160 & Cisurupan & 4 & 0 & 4 \\
\hline 161 & Banyuresmi & 6 & 0 & 6 \\
\hline 161 & Sukarersmi & 2 & 0 & 2 \\
\hline 170 & Samarang & 7 & 0 & 7 \\
\hline 171 & Pasirwangi & 6 & 1 & 5 \\
\hline 181 & Tarogong Kidul & 18 & 3 & 15 \\
\hline 182 & Tarogong Kaler & 8 & 1 & 7 \\
\hline 190 & Garut Kota & 6 & 0 & 6 \\
\hline 200 & Karangpawitan & 7 & 1 & 6 \\
\hline 210 & Wanaraja & 0 & 0 & 0 \\
\hline 211 & Sucinaraja & 2 & 0 & 2 \\
\hline 212 & Pangatikan & 0 & 0 & 0 \\
\hline 220 & Sukawening & 3 & 0 & 3 \\
\hline 221 & Karangtengah & 2 & 0 & 2 \\
\hline 240 & Leles & 2 & 0 & 2 \\
\hline 250 & Leuwigoong & 1 & 0 & 1 \\
\hline 260 & Cibatu & 3 & 0 & 3 \\
\hline 261 & Kersamanah & 3 & 0 & 3 \\
\hline 270 & Cibiuk & 4 & 0 & 4 \\
\hline 280 & Kadungora & 7 & 0 & 7 \\
\hline 290 & $\begin{array}{l}\text { Bulubur } \\
\text { Limbangan }\end{array}$ & 10 & 1 & 9 \\
\hline 300 & Selaawi & 6 & 1 & 5 \\
\hline 310 & Malangbong & 7 & 1 & 6 \\
\hline \multicolumn{2}{|c|}{ TOTAL } & 171 & 14 & 157 \\
\hline
\end{tabular}

dan non akademik. Dalam hal jumlah siswa, berdasarkan pengamatan awal atau observasi pendahuluan minat masyarakat menyekolahkan di SMAM Wanaraja yang peneliti lakukan pada sekolah siswa/siswi di SMAM Wanaraja pada periode tahun 2012-2017 sebagai berikut:

Tabel 2 :

Penerimaan Jumlah Siswa Baru

\begin{tabular}{|c|c|c|c|c|}
\hline No & \multirow{2}{*}{$\begin{array}{c}\text { Tahun } \\
\text { Angkatan }\end{array}$} & \multicolumn{2}{|c|}{ Jurusan } & Jumlah \\
\cline { 3 - 4 } & IPS & IPA & \\
\hline 1 & $2012-2013$ & 30 & 30 & 60 \\
\hline 2 & $2014-2015$ & 32 & 35 & 67 \\
\hline 3 & $2016-2017$ & 30 & 31 & 61 \\
\hline
\end{tabular}

Sumber: Baak SMAM Wanaraja

Bercermin dari hal tersebut diatas pada tahun 2012-2013 siswa dan siswi baru yang sekolah di SMAM Wanaraja sebanyak 60 orang. Sedangkan tahun 2014-2015 jumlah siswa baru yang bersekolah di SMAM Wanaraja meningkat menjadi 67 orang. Akan tetapi ada penurunan siswa dan siswi baru di tahun 2016-2017 yaitu 61 orang.

Walaupun penurunannya tidak signifikan akan tetapi hal tersebut menjadi perhatian dari pihak sekolah yang berupaya terus meningkatkan kualitas maupun kuantitas dari SMAM

Sejalan dengan itu, lembaga pendidikan SMAM Wanaraja merupakan salah satu sekolah yang bernuansa islami di Kec. Wanaraja Kab. Garut yang bergerak dalam bidang jasa layanan pendidikan yang memadai kepada masyarakat di Garut, ini bertujuan untuk memberikan layanan pendidikan kepada masyarakat dengan biaya yang terjangkau oleh semua lapisan masyarakat, baik masyarakat ekonomi lemah maupun menengah atas tanpa memandang kemampuan atau status sosial masyarakat dengan tidak mengurangi kualitas pendidikannya. SMAM Wanaraja berupaya terus meningkatkan kualitas dan kuantitas siswa/siswinya akan tetapi belum menunjukan hasil yang optimal dilihat baru sedikit adanya siswa/siswi yang berprestasi dari akademik

Wanaraja. Oleh karena sebab itu menurut pandangan peneliti ada tiga faktor yang dapat berhubungan terhadap minat masyarakat menyekolahkan di SMAM Wanaraja yaitu harga, kualitas pelayanan danpromosi.

Dari beberapa uraian di atas menurut penulisa untuk membangkitkan minat masyarakat dalam menyekolahkan anak-anaknya sangat bergantung sekali dari beberapa aspek seperti : dari harga yang menjangkau semua lapisan masyarakat, kualitas pelayanan yang maksimal, dan promosi yang sangat aktif sehingga masyarakat mudah dalam mendapatkan informasi tentang sekolah SMAM Wanaraja.

Dengan demikian peneliti tertarik untuk mengkaji lebih mendalam mengenai "Penga- 
ruh Harga, Kualitas Pelayanan dan Promosi terhadap Minat Masyarakat menyekolahkan di SMAM Wanaraja”

\section{Identifikasi Masalah}

Berdasarkan latar belakang penelitian di atas, maka dapat diidentifikasi masalah penelitian yang erat kaitannya dengan hasil belajar siswa, yaitu :

a. Baru sedikit adanya siswa/siswi yang berprestasi dari akademik dan non akademik.

b. Penurunan minat sekolah pada tahun 20122013 siswa dan siswi baru yang sekolah di SMAM Wanaraja sebanyak 60 orang. Sedangkan tahun 2014-2015 jumlah Siswa baru yang bersekolah di SMAM Wanaraja meningkat menjadi 67 orang. Akan tetapi ada penurunan siswa dan siswi baru di tahun 2016-2017 yaitu 61 orang.

c. Kurangnya seperti fasilitas olahraga, lab bahasa yang terbatas.

d. Minimnya informasi-informasi tentang SMAM Wanaraja khususnya di luar Kec. Wanaraja, seperti kurangnya pemasangan spanduk-spanduk, pamplet sekolah.

e. Mendia informasi pun SMAM Wanaraja perlu lebih aktif lagi dalam memberikan pelayanan informasi di Kab. Garut.

\section{Pembatasan Masalah}

Mengingat banyak faktor yang mempengaruhi minat masyarakat, dan terutama karena keterbatasan peneliti dalam hal waktu, tenaga dan biaya, maka perlu dilakukan pembatasan masalah agar lebih fokus dan terarah.

Berdasarkan pertimbangan tersebut penelitian ini hanya akan mengkaji tiga variabel bebas, yaitu : harga, kualitas pelayanan dan promosi,serta satu variabel terikat yaitu minat Masyarakat.

\section{Perumusan Masalah}

Berdasarkan pembatasan masalah di atas, masalah yang akan dikaji dalam penelitian ini dapat dirumuskan sebagai berikut :

a. Apakah terdapat pengaruh positif Harga terhadap kualitas pelayanan kepada masyarakat di SMAM Wanaraja. b. Apakah terdapat pengaruh positif Harga terhadap promosi kepada masyarakat di SMAM Wanaraja.

c. Apakah terdapat pengaruh positif Harga terhadap minat kepada masyarakat di SMAM Wanaraja.

d. Apakah terdapat pengaruh positif Kualitas Pelayanan terhadap promosi kepada masyarakat di SMAM Wanaraja.

e. Apakah terdapat pengaruh positif Kualitas Pelayanan terhadap minat kepada masyarakat di SMAM Wanaraja.

f. Apakah terdapat pengaruh positif Promosi terhadap minat kepada masyarakat di SMAM Wanaraja.

\section{Tujuan Penelitian}

a. Untuk mengetahui Pengaruh Harga terhadap kualitas pelayanan kepada masyarakat di SMAM Wanaraja.

b. Untuk mengetahui Pengaruh Harga terhadap promosi kepada masyarakat di SMAM Wanaraja.

c. Untuk mengetahui Pengaruh Harga terhadap minat kepada masyarakat di SMAM Wanaraja.

d. Untuk mengetahui Pengaruh Kualitas Pelayanan terhadap promosi kepada masyarakat di SMAM Wanaraja.

e. Untuk mengetahui Pengaruh Kualitas Pelayanan terhadap minat kepada masyarakat di SMAM Wanaraja.

f. Untuk mengetahui Pengaruh Promosi terhadap minat kepada masyarakat di SMAM Wanaraja.

\section{Urgensi Penelitian}

Penelitian pada area yang sama khususnya mengenai faktor-faktor pengaruh harga, kualitas pelayanan dan promosi terhadap minat yang telah banyak dilakukan oleh peneliti-peneliti terdahulu yang sifatnya individual maupun kelompok. Akan tetapi hasil dari penelitian tersebut masih menghasilkan hasil yang berbeda-beda. Oleh sebab itu penulis tertarik lebih mendalam dalam penelitian ini untuk membuktikan hasil dari pengaruh antar variabel harga, kualitas pelayanan dan promosi terhadap minat. 


\section{TINJAUAN PUSTAKA}

\section{Definisi Minat}

Adapun minat menurut Bernard menyebutkan, minat adalah dorongan yang ada diantara individu dan objek-objek, situasi orang atau kegiatan (Bernard H.W. 1970). Minat merupakan perasaan senang yang mewarnai setiap individu yang ditimbulkan oleh situasi orang kearah mana energi mental atau fisik tertentu. Minat adalah kecenderungan untuk ikut serta aktif dalam pengalaman-pengalaman dan memelihara pengalaman tersebut (Walter V, Bingharmm, 1949). Minat dapat dikatakan lawan keengganan yangdirumuskan sebagai kecenderungan untuk menjauhi terjadinya pengalaman tentang objek-objek. Minat dapat menjadi indikator dari kekuatan seseorang di area tertentu dimana ia akan termotivasi untuk mempelajarinya dan menunjukan kinerja yang tingg.

\section{Definisi Harga}

Menurut (Philip Kotler \& Gary Armstrong, 2008) harga (Price) adalah jumlah yang ditagihkan atas semua produk atau jasa. Pengertian harga yang lebih luas adalah jumlah semua nilai yang diberikan oleh pelanggan untuk mendapatkan keuntungan dari memiliki atau menggunakan suatu produk atau jasa. Sepanjang sejarahnya harga telah menjadi faktor utama yang mempengaruhi pilihan para pembeli.

\section{Definisi Kualitas Pelayanan}

Menurut (Rambat Lupiyoadi dan A. Hamdani, 2011.175) kualitas bersifat relative tergantung dari pespektif yang digunakan untuk menentukan ciri-ciri dan spesifikasi. Pada dasarnya terdapat tiga orientasi kualitas yang seharusnya konsisten satu sama lain: Persepsi konsumen, Produk (Jasa), dan proses. Untuk berwujud barang, ketiga orientasi ini jelas dapat dibedakan, tetapi untuk jasa produk dan proses mungkin tidak dapat dibedakan dengan jelas, bahkan produknya adalah proses itu sendiri.

\section{Defenisi pemasaran}

Pemasaran adalah proses dimana perusahaan menciptakan nilai bagi pelangan dan memba- ngun hubungan yang kuat dengan pelanggan dengan tujuan untuk menangkap nilai dari pelanggan sebagai imbalannya (Philip Kotler dan Gary Amstrong,2008). Pemasaran adalah kegiatan manusia yang diarahkan untuk memenuhi dan memuaskan kebutuhan dan keinginan melalui proses pertukaran (Sofjan Assauri, 2010).

\section{Defenisi Promosi Penjualan}

Promosi penjualan adalah semua kegiatan yang dimaksudkan untuk meningkatkan arus barang atau jasa dari produsen sampai pada penjualan akhir point of sales terdiri atas brosur, lembar informasi (Rambat Lupiyoadi dan A. Hamdani.2011).

Promosi penjualan (sales promotion) adalah kegiatan promosi jangka pendek yang dirancang untuk merancang konsumen agar membeli atau bekerja sama dengan distributor, agar penjualan, atau anggota dagang lainnya (Ronal J Ebert dan Ricky W Graffin. 2007). Menurut (Mahmud Machfoedz. 2010) Berbagai sarana promosi yang didesain untuk memotivasi respon pasar lebih awal. Promosi penjualan dapat berupa promosi konsumen semisal contoh produk, kupon, potongan harga dan sebagainya: promosi perdagangan seperti produk gratis, keringanan harga pembelian dan sebagainya.

\section{Tujuan Promosi}

Secara umum tujuan-tujuan dari promosi penjualan dapat digeneraisasikan menjadi tiga: Meningkatkan permitaan dari pada pengguna indrustri dan atau konsumen akhir: Meningkatkan kinerja bisnis, Mendukung dan mengoordinasikan kegiatan penjualan personal dan iklan. Menuruh (Mahmud Machfoed, 2010) tujaun promosi penjuaan dapat disebutkan sebagai berikut: Mengidentifikasi dan menarik konsumen baru, Mengkomunikasikan produk baru, Meningkatkan jumlah konsumen untuk produk yang telah dikenal secara luas, Menginformasikan kepada konsumen tentang peninkatan kualitas product, Mengajak konsumen untuk mendatangi toko tempat penjualan produk, dan memotivasi konsumen agar membeli produk. 


\section{Sasaran Promosi Penjualan}

Alat promosi konsumen merupakan sarana promosi penjualan yang digunakan untuk mendorong konsumen melkukan pembelian jangka pendek dan menjalin hubungan jangka panjang. Dalam hal ini saran yang diperlukan untuk konsumen akhir, dimana alat promosi utamanya meliputi sample produk, kupon, pengembalian tunai, harga khusus, undian, dan lainnya.

\section{Krangka Pikir dan Hipotesis}

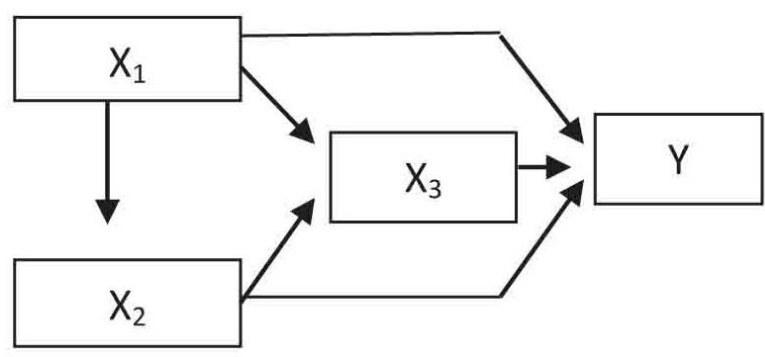

Sumber: Data diolah untuk keperluan Penelitian

Gambar 2.2: Bagan Kerangka Berpikir

\section{Hipotesis}

Berdasarkan kerangka berpikir yang disusun dengan berlandaskan pada deskripsi teori diatas maka dapat diajukan hipotesis sehagai berkut:

a. Harga secara signifikan berpengaruh positif terhadap kualitas pelayanan kepada masyarakat di SMAM Wanaraja.

b. Harga secara signifikan berpengaruh positif terhadap promosi kepada masyarakat di SMAM Wanaraja.

c. Harga secara signifikan berpengaruh positif terhadap minat kepada masyarakat di SMAM Wanaraja.

d. Kualitas pelayanan secara signifikan berpengaruh positif terhadap promosi kepada masyarakat di SMAM Wanaraja..

e. Kualitas pelayanan secara signifikan berpengaruh positif terhadap minat kepada masyarakat di SMAM Wanaraja. f. Promosi secara signifikan berpengaruh positif terhadap minat kepada masyarakat di SMAM Wanaraja.

\section{Metodelogi Penelitian}

Berdasarkan tujuan yang ingin di capai dan pengaruh antar variable, maka penelitian ini termasuk penelitian kuantitatif. Adapun variable-variabel dalam penelitian ini terdiri dari variable independent yaitu Harga (XI), Kualitas Pelayanan (X2), Promosi (X3), serta variable dependen yaitu Minat masyarakat (Y). Populasi dalam penelitian ini adalah seluruh siswa yang terdaftar aktif di sekolah SMAM Wanaraja. Siswa yang terdaftar di SMAM Wanaraja pada tahun 2016-2017 sebanyak 191 siswa sebagai ukuran populasi (N) sehingga dalam penelitian ini sampel dengan menggunakan rumus Slovin terdapat 129 orang dari populasi 191 orang dan ujicoba sebanyak 30 orang yang tidak termasuk sampel.

Uji yang dipake dalam melakukan penelitian ini:

\section{Uji Persyaratan Analisis}

\section{Uji Normalitas}

Uji normalitas bertujuan untuk menguji apakah dalam modelregresi, variabel independen dan variabel dependen keduanya mempunyai distribusi normal atau mendekati normal (Imam Ghozali, 2011: 160). Dalam penelitian ini, uji normalitas menggunakan Normal ProbabilityPlot (P-P Plot). Suatu variabel dikatakan normal jika gambar distribus dengan titik-titik data yang menyebar di sekitar garis diagonal, dan penyebaran titiktitik data searah mengikuti garis diagonal.

\section{Uji Homogenitas}

Pengujian homogenitas adalah pengujian mengenai sama tidaknya variansi - variansi dua buah distribusi atau lebih. Uji homogenitas yang akan dibahas dalam tulisan ini adalah Uji Homogenitas Variansi dan Uji Bartlett. Uji homogenitas dilakukan untuk mengetahui apakah data dalam variabel $\mathrm{X}$ dan $\mathrm{Y}$ bersifat homogen atau tidak. 


\section{Uji Linearitas}

Uji linearitas digunakan untuk mengetahui apakah hubungan antar variabel bebas dan variabel terikatnya linear. Kriteria yang digunakan adalah dengan uji F. Apabila nilai sig $\mathrm{F}$ tersebut kurang 55 dari 0,05 maka hubungannya tidak linear, sedangkan jika nilai sig F lebih besar dari atau sama dengan 0,05 maka hubungannya linear.

\section{Uji Signifikasi (Uji t dan F)}

Uji hipotesis adalah uji sederhana yang dilakukan untuk menentukan diterima atau ditolaknya hipotesis. Selain itu, juga digunakan untuk mengui apakah hubungan yang ditemukan tersebut berlaku untuk seluruh populasi. Rumus uji signifikasi ( $t$ hitung) korelasi person product moment adalah:

Dimana:

$$
\begin{array}{ll}
\mathrm{t} & =\mathrm{t} \text { hitung } \\
\mathrm{r} & =\text { koefisien korelasi } \\
\mathrm{n} & =\text { jumlah sampel }
\end{array}
$$

Selanjutnya uji signifikasi diuji dengan uji $\mathrm{F}$ Dimana:

$$
\begin{array}{ll}
\mathrm{R} & =\text { Koefisien korelasi } \\
\mathrm{K} & \text { = Jumlah variabel indevenden } \\
\mathrm{N} & \text { = Jumlah Anggota sampel }
\end{array}
$$

\section{Koefisien Korelasi}

Analisa korelasi berguna untuk menentukan suatu besaran yang menyatakan bagaimana kuatnya hubungan suatu variabel dengan variabel lainnya. Variabel $\mathrm{X}$ dan variabel $\mathrm{Y}$ dimana variabel $X$ adalah motivasi sebagai variabel yang mempengaruhi dan variabel $Y$ adalah Kedisiplinan kerja sebagai variable yang dipengaruhi dengan perhitungan sebagai berikut:

Keterangan:

$\begin{array}{ll}\mathrm{r} & =\text { Koefisien korelasi } \\ \sum \mathrm{X} & =\text { Jumlah skor item } \\ \sum \mathrm{Y} & =\text { Jumlah skor total } \\ \mathrm{N} & =\text { Jumlah responden }\end{array}$
Untuk mengetahui apakah suatu koefisien korelasi tersebut termasuk kuat atau lemahnya koefisien tersebut dapat dilihat dibawah ini:

\begin{tabular}{|c|c|}
\hline $\begin{array}{c}\text { Interval } \\
\text { Koevisien }\end{array}$ & $\begin{array}{c}\text { Tingkat } \\
\text { Hubungan }\end{array}$ \\
\hline $0.00-0.199$ & Sangat Rendah \\
\hline $0.20-0.399$ & Rendah \\
\hline $0.40-0.599$ & Sedang \\
\hline $0.60-0.799$ & Kuat \\
\hline $0.80-1.000$ & Sangat Kuat \\
\hline
\end{tabular}

\section{HASIL PENELITIAN DAN PEMBAHASAN}

\section{Uji Normalitas}

Uji normalitas distribusi frekuensi dari variabel $\mathrm{X}_{1}, \mathrm{X}_{2}, \mathrm{X}_{3}$ dan $\mathrm{X}_{4}$ dilakukan denganuji normalitas Kolmogorov Smirnov. Sesuai de-

\begin{tabular}{|c|c|c|c|c|c|}
\hline & & Harga & $\begin{array}{c}\text { Kualit } \\
\text { as }\end{array}$ & \begin{tabular}{|c|} 
Promo \\
si
\end{tabular} & Minat \\
\hline \multicolumn{2}{|l|}{$\bar{N}$} & 129 & 129 & 129 & 129 \\
\hline \multirow{2}{*}{$\begin{array}{l}\text { Normal } \\
\text { Parameters }\end{array}$} & Mean & 67.47 & 61.16 & 70.69 & 64.81 \\
\hline & Std. Deviation & 9.717 & 12.00 & 10.06 & 8.73 \\
\hline \multirow{3}{*}{$\begin{array}{l}\text { Most } \\
\text { Extreme } \\
\text { Differences }\end{array}$} & Absolute & .081 & .072 & .078 & .086 \\
\hline & Positive & .081 & .072 & .078 & .086 \\
\hline & Negative & -.081 & -.066 & -.068 & -.064 \\
\hline \multicolumn{2}{|c|}{ Test Statistic } & .081 & .072 & .078 & .086 \\
\hline \multicolumn{2}{|c|}{ Asymp. Sig. (2-tailed) } & .035 & .099 & .052 & .020 \\
\hline
\end{tabular}
ngan ketentuannya, kriteria normalitas menurut uji Kolmogorov Smirnov adalah apabila Sig. (2-tailed) > 0.05 maka data berdistribusi normal. Hasil perhitungan uji normalitas tersaji pada tabel berikut.

Test of Homogeneity of Variances X1

\begin{tabular}{|c|c|c|c|}
\hline $\begin{array}{c}\text { Levene } \\
\text { Statistic }\end{array}$ & df1 & df2 & Sig. \\
\hline 1.412 & 26 & 92 & .118 \\
\hline
\end{tabular}

Test of Homogeneity of Variances X2

\begin{tabular}{|c|c|c|c|}
\hline $\begin{array}{c}\text { Levene } \\
\text { Statistic }\end{array}$ & df1 & df2 & Sig. \\
\hline 1.394 & 29 & 87 & .121 \\
\hline
\end{tabular}


Test of Homogeneity of Variances X3

\begin{tabular}{|c|c|c|c|}
\hline $\begin{array}{c}\text { Levene } \\
\text { Statistic }\end{array}$ & df1 & df2 & Sig. \\
\hline 1.394 & 29 & 87 & .121 \\
\hline
\end{tabular}

Berdasarkan output diatas, diketahui bahwa nilai signifikansi sebesar $>0.05$ sehingga dapat disimpulkan bahwa data yang diuji berdistribusi normal. Hasil data tersebut terangkum pada tabel dibawah ini:

\begin{tabular}{|c|c|c|c|c|}
\hline Variabel & $\mathbf{N}$ & Sig.hitung & $\mathbf{A}$ & Keterangan \\
\hline$X_{1}$ & 129 & 0.035 & 0.05 & Normal \\
\hline$X_{2}$ & 129 & 0.099 & 0.05 & Normal \\
\hline$X_{3}$ & 129 & 0.052 & 0.05 & Normal \\
\hline$X_{4}$ & 129 & 0.020 & 0.05 & Normal \\
\hline
\end{tabular}

Selain dengan statistik Kolmogorov Smirnov, uji normlitas dapat dilihat melalui tampilan grafik histogram maupun grafik normal Scatterplot.

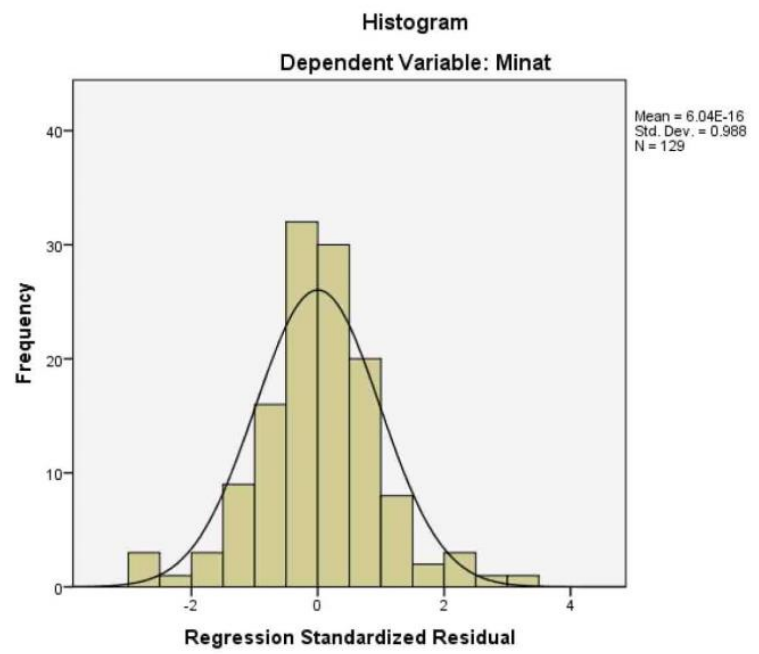

Garis grafik ini menggambarkan keadaan ideal dari data yang mengikuti distribusi normal. Titik-titik selalu mengikuti dan mendekati garis diagonalnya, oleh kareana itu dapat disimpulkan bahwa nilai residual berdistribusi normal, maka disimpulkan data berdistribusi normal.
Normal P.P Plot of Regression Standardized Residual

\section{Dependent Variable: Minat}

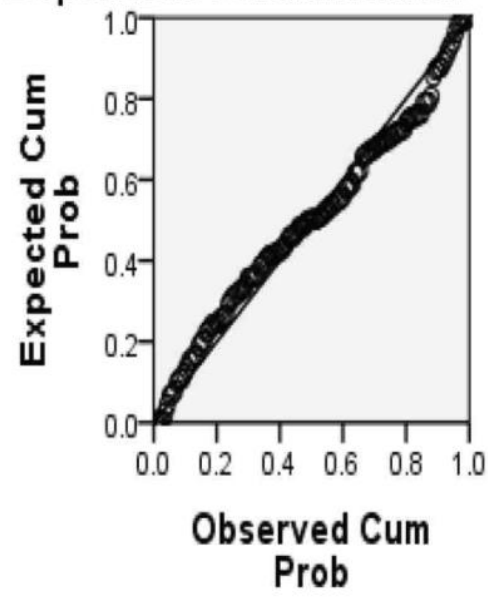

\section{Uji Homogenitas}

Pengujian homogenitas adalah pengujian mengenai sama tidaknya variansi-variansi dua buah distribusi atau lebih. Uji statistic yang digunakan adalah menggunakan levane test.Penggunaan homogegenitas menggunakan program SPSS 22 dengan keriteria pengujian adalah:

Ho $=$ Homogen, jika probalitas $>0.05 \mathrm{Ho}$ diterima Jika Sig>0.05 maka Ho diterima dan H1 ditolak.

$\mathrm{H} 1$ = Tidak homogen, jika probalitas $<0.05$ Ho ditolak. Jika sig $<0.05$ maka Ho ditolak dan H1 diterima.

Dari hasil analisis pada table test of homogeneity Variances diperoleh nilai probalitas (sig) adalah $0.118>0.05$ untuk Variabel, $\mathrm{X}_{1}, 0.121>0.05$ untuk variabel $\mathrm{X}_{2}$ dan 0.116 untuk variable $\mathrm{X}_{3}$.

\section{Uji Linearitas}

Sebelum persamaan regresi dapat digunakan, maka perlu dilakukan uji kelinieran persamaaan regresi. Hipotesis statistika yang digunakan adalah sebagai berikut:

$\mathrm{H} 0: \beta=0$ (model regresi tidak linear)

Ha $: \beta \neq 0$ (model regresi linear).

Kita lihat table berikut: 


\begin{tabular}{|l|r|r|r|r|l|}
\hline & $\begin{array}{c}\text { Sum of } \\
\text { Squares }\end{array}$ & df & $\begin{array}{c}\text { Mean } \\
\text { Square }\end{array}$ & F & Sig. \\
\hline (Comb) & 4272.74 & 36 & 118.68 & 1.99 & .004 \\
\hline Linearity & 2056.37 & 1 & 2056.37 & 34.50 & .000 \\
\hline $\begin{array}{l}\text { Deviation } \\
\text { from } \\
\text { Linearity }\end{array}$ & 2216.36 & 35 & 63.32 & 1.06 & .398 \\
\hline $\begin{array}{l}\text { Within } \\
\text { Groups }\end{array}$ & 5482.79 & 92 & 59.59 & & .004 \\
\hline Total & $\mathbf{9 7 5 5 . 5 3}$ & $\mathbf{1 2 8}$ & & & \\
\hline
\end{tabular}

\begin{tabular}{|l|l|l|l|l|l|}
\hline & $\begin{array}{c}\text { Sum of } \\
\text { Squares }\end{array}$ & \multicolumn{1}{|c|}{$\mathrm{df}$} & $\begin{array}{c}\text { Mean } \\
\text { Square }\end{array}$ & $\mathrm{F}$ & Sig. \\
\hline $\begin{array}{l}\text { (Combin } \\
\text { ed) }\end{array}$ & 4272.74 & 36 & 118.68 & .92 & .600 \\
\hline Linearity & 2056.37 & 1 & 2056.37 & 2.25 & .137 \\
\hline $\begin{array}{l}\text { Deviation } \\
\text { from } \\
\text { Linearity }\end{array}$ & 2216.36 & 35 & 63.32 & .893 & .649 \\
\hline $\begin{array}{l}\text { Within } \\
\text { Groups }\end{array}$ & 5482.79 & 92 & 59.59 & & .600 \\
\hline Total & 9755.53 & 128 & & & \\
\hline
\end{tabular}

\begin{tabular}{|l|r|r|r|r|r|}
\hline & \multicolumn{1}{|c|}{$\begin{array}{c}\text { Sum of } \\
\text { Squares }\end{array}$} & \multicolumn{1}{c|}{$\mathrm{df}$} & $\begin{array}{c}\text { Mean } \\
\text { Square }\end{array}$ & \multicolumn{1}{c|}{$\mathrm{F}$} & Sig. \\
\hline \multicolumn{1}{|c|}{ (Comb) } & 3890.21 & 43 & 90.47 & 1.31 & .144 \\
\hline Linearity & 597.43 & 1 & 597.43 & 8.65 & .004 \\
\hline $\begin{array}{l}\text { Deviation } \\
\text { from } \\
\text { Linearity }\end{array}$ & 3292.77 & 42 & 78.39 & 1.13 & .305 \\
\hline $\begin{array}{l}\text { Within } \\
\text { Groups }\end{array}$ & 5865.32 & 85 & 69.00 & & \\
\hline Total & 9755.53 & 128 & & \multicolumn{2}{|l|}{} \\
\hline
\end{tabular}

Sumber: Hasil PEngolahan Data SPSS 22

Dalam penelitian ini, untuk mempermudah dalam perhitungan maka digunakan bantuan program SPSS 22. Hasil perhitungan tersebut dapat dilihat pada hasiloutput SPSS diatas. Untuk $\mathrm{X}_{1}$ diperoleh sig 0.39, $\mathrm{X}_{2}$ sebesar 0.64 dan $X_{3}$ sebesar 0.30. Hasil tersebut menunjukkan bahwa jika nilai signifikasi lebih besar dari 0.05, maka kesimpulannya adalah terdapat hubungan linier secara signifikan antara variable harga $\left(\mathrm{X}_{1}\right)$, kualitas pelayanan $\left(\mathrm{X}_{2}\right)$, promosi $\left(\mathrm{X}_{3}\right)$ terhadap minat mahasiswa $(\mathrm{Y})$.

\section{Uji Signifikansi (uji t dan uji f) Uji-t}

Menilai apakah mean dan keragaman dari dua kelompok berbeda secara statistik satu sama lain. Analisis ini digunakan apabila kita ingin membandingkan mean dan keragaman dari dua kelompok data, dan cocok sebagai analisis dua kelompok rancangan percobaan acak:

Hipotesis statistik :

Ha $: \mu_{0}<0.05$

Ho : $\mu_{0} \geq 0.05$

\section{Parameter uji :}

Jika-t tabel $\leq \mathrm{t}$ hitung maka Ho diterima, dan Ha di tolak.

Jika-t tabel $>\mathrm{t}$ hitung maka Ho ditolak, dan Ha diterima.Kita lihat tabel berikut:

\begin{tabular}{|c|c|c|c|c|}
\hline \multicolumn{5}{|c|}{$\begin{array}{c}\text { Signifikansi } \\
\text { One-Sample Statistics }\end{array}$} \\
\hline & $\mathrm{N}$ & Mean & $\begin{array}{c}\text { Std. } \\
\text { Deviation }\end{array}$ & $\begin{array}{c}\text { Std. Error } \\
\text { Mean }\end{array}$ \\
\hline Harga & 129 & 67.47 & 9.71 & .85 \\
\hline Kualitas & 129 & 61.16 & 12.00 & 1.05 \\
\hline Promosi & 129 & 64.72 & 12.74 & 1.12 \\
\hline Minat & 129 & 64.81 & 8.73 & .76 \\
\hline
\end{tabular}

Hasil uji di atas menunjukkan bahwa t hitung untuk variabel harga $\left(X_{1}\right)$. $=78.86$. untuk variable kualitas pelayanan $=57.88,\left(\mathrm{X}_{2}\right)$. $\operatorname{promosi}\left(\mathrm{X}_{3}\right) .=57.67$. Dan minat masyarakat $\left(\mathrm{X}_{4}\right)=84.32$. diperoleh dengan $\mathrm{df}=128$, sig $5 \%$. Karena $-\mathrm{t}$ tabel < dari $\mathrm{t}$ hitung, maka Ho diterima, artinya tingkat keberhasilan cukup tinggi.

\begin{tabular}{|c|c|c|c|c|c|c|}
\hline & \multicolumn{6}{|c|}{ Test Value $=0$} \\
\hline & \multirow[b]{2}{*}{$\mathrm{t}$} & \multirow[b]{2}{*}{$\mathrm{df}$} & \multirow{2}{*}{$\begin{array}{c}\text { Sig. } \\
\text { (2-tailed) }\end{array}$} & \multirow{2}{*}{$\begin{array}{c}\text { Mean } \\
\text { Difference }\end{array}$} & \multicolumn{2}{|c|}{$\begin{array}{l}95 \% \text { Confidence } \\
\text { Interval of the } \\
\text { Difference }\end{array}$} \\
\hline & & & & & Lower & Upper \\
\hline Harga & 78.86 & 128 & .000 & 67.47 & 65.78 & 69.16 \\
\hline Kualitas & 57.88 & 128 & .000 & 61.16 & 59.07 & 63.25 \\
\hline Promosi & 57.67 & 128 & .000 & 64.72 & 62.50 & 66.94 \\
\hline Minat & 84.32 & 128 & .000 & 64.81 & 63.29 & 66.33 \\
\hline
\end{tabular}

Uji F Uji simultan atau disebut juga uji F dalam analisis regresi linear berganda bertujuan untuk mengetahui apakah variabel bebas (X) secara bersama-sama atau secara serempak (simultan) berpengaruh terhadap 
variabel terikat (Y). Untuk melihat $\mathrm{F}$ tabel dalam pengujian hipotesis pada model regresi, perlu menentukan derajat bebas atau degree of freedom dengan menggunakan rumus $\mathrm{F}$ table $=\mathrm{F}(\mathrm{k}: \mathrm{n}-\mathrm{k})=\mathrm{F}(4: 125)=2.44$

Berdasarkan hasil output SPSS di atas kita dapat melihat dimana nilai $\mathrm{F}$ hitung lebih besar dari pada nilai $\mathrm{F}$ tabel $(70.041>2.44)$ dengan tingkat signifikan di bawah 0.05 yaitu 0.00. Berdasarkan cara pengambilan keputusan uji simultan dalam analisis regresi dapat disimpulkan bahwa variabel Harga $\left(\mathrm{X}_{1}\right)$, Kualitas Pelayaanan $\left(\mathrm{X}_{2}\right)$, dan Promosi $\left(\mathrm{X}_{3}\right)$ jika diuji secara bersama-sama atau serempak berpengaruh signifikan terhadap peningkatan Minat Masyarakat (Y).

\begin{tabular}{|c|c|c|c|c|c|}
\hline \multicolumn{6}{|c|}{ ANOVA $^{a}$} \\
\hline Model & $\begin{array}{l}\text { Sum of } \\
\text { Squares }\end{array}$ & df & $\begin{array}{c}\text { Mean } \\
\text { Square }\end{array}$ & $\mathrm{F}$ & Sig. \\
\hline 1 Regression & 5598.245 & 3 & 1866.082 & 70.041 & .000 \\
\hline Residual & 3303.684 & 124 & 26.643 & & \\
\hline Total & 8901.930 & 127 & & & \\
\hline
\end{tabular}

a. Dependent Variable: Y

b. Predictors: (Constant), X3, X2, X1

\section{Pengujian Hipotesis}

Pengujian hipotesis dilakukan guna mengetahui apakah hipotesis yang diungkapkan dalam penelitian ini dapat diterima atau ditolak. Berdasarkan hasil uji persyaratan ternyata pengujian hipotesis dapat dilakukan, sebab sejumlah persyaratan yang ditentukan untuk pengujian hipotesis telah dipenuhi.

\section{Analisis Korelasi}

Analisis korelasi bertujuan untuk melihat keeratan atau hubungan antara 2 variabel atau lebih. Korelasi antara variabel harga, kualitas pelayanan, dan minat masyarakat:

\section{Pedoman untuk memberikan interpretasi Koefisien Korelasi}

\begin{tabular}{|l|c|c|}
\hline NO & $\begin{array}{c}\text { Koefisien } \\
\text { Korelasi }\end{array}$ & Keterangan \\
\hline 1 & $0.00-0.199$ & Korelasi Sangat Rendah \\
\hline 2 & $0.20-0.399$ & Korelasi Rendah \\
\hline 3 & $0.40-0.599$ & Korelasi Sedang \\
\hline 4 & $0.60-0.799$ & Korelasi Kuat \\
\hline 5 & $0.80-1.000$ & Korelasi Sangat Kuat \\
\hline
\end{tabular}

a) Korelasi harga $\left(\mathrm{X}_{1}\right)$ terhadap kualitas pelayanan $\left(\mathrm{X}_{2}\right)$.

\section{Model Summary Variabel $\mathbf{X}_{1}-\mathbf{X}_{2}$}

\begin{tabular}{|c|c|c|c|c|}
\multicolumn{7}{c|}{ Model Summary } \\
\hline Model & R & R Square & $\begin{array}{c}\text { Adjusted R } \\
\text { Square }\end{array}$ & $\begin{array}{c}\text { Std. Error of } \\
\text { the Estimate }\end{array}$ \\
\hline 1 & .238 & .056 & .049 & 6.116 \\
\hline
\end{tabular}

a. Predictors: (Constant), X1

b) Pengaruh harga $\left(X_{1}\right)$ terhadap promosi $\left(\mathrm{X}_{3}\right)$.

\section{Model Summary Variabel $\mathbf{X}_{1}-\mathbf{X}_{3}$}

\begin{tabular}{|c|c|c|c|c|}
\hline \multicolumn{5}{|c|}{ Model Summary } \\
Model & $\mathrm{R}$ & R Square & $\begin{array}{c}\text { Adjusted R } \\
\text { Square }\end{array}$ & $\begin{array}{c}\text { Std. Error of } \\
\text { the Estimate }\end{array}$ \\
\hline 1 & .447 & .200 & .193 & 9.038 \\
\hline
\end{tabular}

a. Predictors: (Constant), X1

\begin{tabular}{|ll|r|r|r|r|}
\multicolumn{7}{|c|}{ Correlations } \\
\hline & \multicolumn{1}{|c|}{ X1 } & \multicolumn{1}{c|}{ X2 } & \multicolumn{1}{c|}{ X3 } & \multicolumn{1}{c|}{ Y } \\
\hline X1 & Pearson Correlation & 1 & $.238^{* *}$ & $.447^{* *}$ & $.502^{* *}$ \\
& Sig. (2-tailed) & & .007 & .000 & .000 \\
& $\mathrm{~N}$ & 129 & 129 & 129 & 129 \\
\hline X2 & Pearson Correlation & $.238^{* *}$ & 1 & $.392^{* *}$ & $.431^{* * *}$ \\
& Sig. (2-tailed) & .007 & & .000 & .000 \\
& $\mathrm{~N}$ & 129 & 129 & 129 & 129 \\
\hline X3 & Pearson Correlation & $.447^{* *}$ & $.392^{* *}$ & 1 & $.762^{* *}$ \\
& Sig. (2-tailed) & .000 & .000 & & .000 \\
& N & 129 & 129 & 129 & 129 \\
\hline Y & Pearson Correlation & $.502^{* * *}$ & $.431^{* *}$ & $.762^{* *}$ & 1 \\
& Sig. (2-tailed) & .000 & .000 & .000 & \\
& N & 129 & 129 & 129 & 129 \\
\hline
\end{tabular}

c) Pengaruh harga $\left(X_{1}\right)$ terhadap minat masyarakat (Y).

\section{Model Summary Variabel $\mathbf{X}_{1}-\mathbf{X}_{4}$}

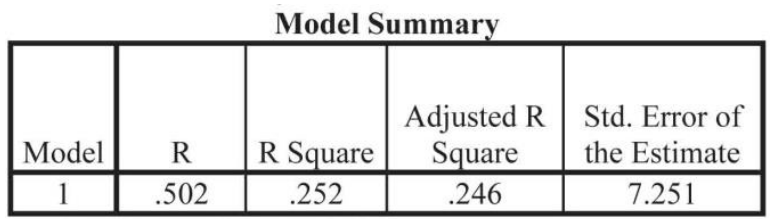

a. Predictors: (Constant), X1

d) Pengaruh kualitas pelayanan $\left(X_{2}\right)$ terhadap promosi $\left(\mathrm{X}_{3}\right)$

Model Summary Variabel $\mathbf{X}_{1}-\mathbf{X}_{3}$

\begin{tabular}{|c|c|c|c|c|}
\hline \multicolumn{5}{|c|}{ Model Summary } \\
\hline Model & $\mathrm{R}$ & R Square & $\begin{array}{c}\text { Adjusted R } \\
\text { Square }\end{array}$ & $\begin{array}{c}\text { Std. Error of } \\
\text { the Estimate }\end{array}$ \\
\hline 1 & .431 & .186 & .179 & 7.567 \\
\hline \multicolumn{4}{|c|}{ a. Predictors: (Constant), X2 } \\
\hline
\end{tabular}


e) Pengaruh hkualiatas pelayanan terhadap minat masyarakat $(\mathrm{Y})$.

Model Summary Variabel $\mathbf{X}_{2}-\mathbf{X}_{4}$

\begin{tabular}{|c|c|c|c|c|}
\hline \multicolumn{5}{|c|}{ Model Summary } \\
\hline Model & $\mathrm{R}$ & R Square & $\begin{array}{c}\text { Adjusted R } \\
\text { Square }\end{array}$ & $\begin{array}{c}\text { Std. Error of } \\
\text { the Estimate }\end{array}$ \\
\hline 1 & .392 & .154 & .147 & 9.292 \\
\hline \multicolumn{4}{|c|}{ a. Predictors: (Constant), X2 } \\
\hline
\end{tabular}

f) Pengaruh Promosi $\left(\mathrm{X}_{3}\right)$ terhadap Minat Masyarakat (Y).

Model Summary Variabel $\mathbf{X}_{2^{-}} \mathbf{X}_{3}$

\begin{tabular}{|c|c|c|c|c|}
\hline \multicolumn{5}{|c|}{ Model Summary } \\
\hline Model & $\mathrm{R}$ & R Square & $\begin{array}{c}\text { Adjusted R } \\
\text { Square }\end{array}$ & $\begin{array}{c}\text { Std. Error of } \\
\text { the Estimate }\end{array}$ \\
\hline 1 & .447 & .200 & .193 & 9.038 \\
\hline a. Predictors: (Constant), X1 \\
\hline
\end{tabular}

Rangkuman Analisis Korelasi

\begin{tabular}{|c|c|c|c|c|c|}
\hline No & Kelompok & $\begin{array}{c}\text { Koefisien } \\
\text { Korelasi }\end{array}$ & Sig & & Keterangan \\
\hline 1 & $\mathrm{X}_{1}$ atas $\mathrm{X}_{2}$ & 0.238 & 0.000 & 0.05 & Korelasi Erat \\
\hline 2 & $\mathrm{X}_{1}$ atas $\mathrm{X}_{3}$ & 0.447 & 0.000 & 0.05 & Korelasi Erat \\
\hline 3 & $\mathrm{X}_{1}$ atas $\mathrm{Y}$ & 0.502 & 0.000 & 0.05 & Korelasi Erat \\
\hline 4 & $\mathrm{X}_{2}$ atas $\mathrm{X}_{3}$ & 0.392 & 0.000 & 0.05 & Korelasi Erat \\
\hline 5 & $\mathrm{X}_{2}$ atas $\mathrm{Y}$ & 0.431 & 0.000 & 0.05 & $\begin{array}{c}\text { Korelasi } \\
\text { Sangat Erat }\end{array}$ \\
\hline 6 & $\mathrm{X}_{3}$ atas $\mathrm{Y}$ & 0.762 & 0.000 & 0.05 & $\begin{array}{c}\text { Korelasi } \\
\text { Sangat Erat }\end{array}$ \\
\hline
\end{tabular}

\section{Path Analysis (Analisis Jalur) Matriks Korelasi}

\begin{tabular}{|l|c|c|c|r|}
\hline & $\mathbf{X}_{1}$ & $\mathbf{X}_{\mathbf{2}}$ & $\mathbf{X}_{\mathbf{3}}$ & $\mathbf{X}_{4}$ \\
\hline $\mathbf{X}_{1}$ & 1 & 0.238 & 0.447 & 0.502 \\
\hline $\mathbf{X}_{2}$ & & 1 & 0.392 & 0.431 \\
\hline $\mathbf{X}_{3}$ & & & 1 & 0.762 \\
\hline $\mathbf{X}_{4}$ & & & & 1 \\
\hline
\end{tabular}

\section{Mencari persamaaan koefisen Jalur}

$$
\begin{aligned}
& \mathrm{r}_{12}=\mathrm{P}_{21} \\
& \mathrm{r}_{13}=\mathrm{p}_{31}+\mathrm{p}_{32} \mathrm{r}_{12} \\
& \mathrm{r}_{23}=\mathrm{p}_{31} \mathrm{r}_{12}+\mathrm{p}_{32} \\
& \mathrm{r}_{14}=\mathrm{p}_{41}+\mathrm{p}_{42} \mathrm{r}_{21}+\mathrm{p}_{43} \mathrm{r}_{31} \\
& \mathrm{r}_{24}=\mathrm{p}_{41} \mathrm{r}_{12}+\mathrm{p}_{42}+\mathrm{p}_{43} \mathrm{r}_{32} \\
& \mathrm{r}_{34}=\mathrm{p}_{41} \mathrm{r}_{31}+\mathrm{p}_{42} \mathrm{r}_{32}+\mathrm{p}_{43}
\end{aligned}
$$

$\left(\mathrm{X}_{2}\right) \quad$ Hasil Koefisen Jalur

Beta $=$ Koefisen regresi tersetandar, digunakan sebagai jalur :
$\mathrm{P}_{21}=0.238$
$\mathrm{P}_{31}=0.375$
$P_{32}=0.303$
$\mathrm{P}_{41}=0.191$
$\mathrm{P}_{42}=0.142$
$\mathrm{P}_{43}=0.620$

Disajikan dalam diagram jalur dalam gambar berikut :

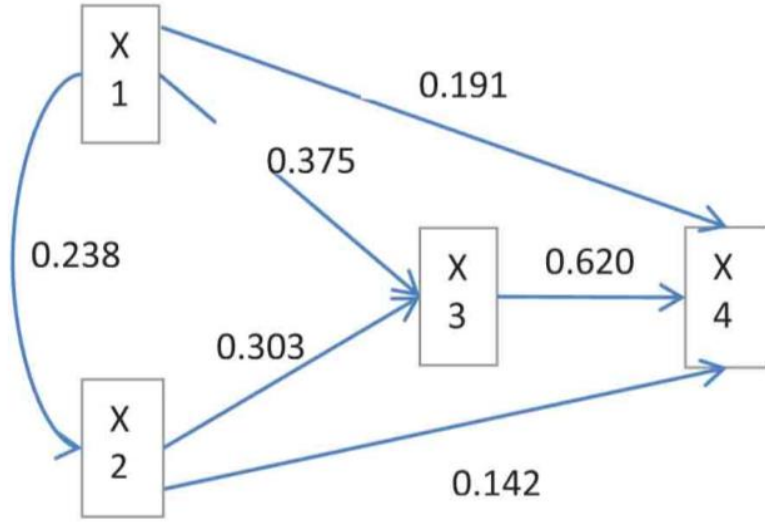

\section{Kesimpulan}

a. Hipotesis Kesatu secara teoritik menduga bahwa Harga mempengaruhi Kualitas Pelayanan.Hasil pengujian yang diperoleh bahwa terdapat pengaruh secara positif dan signifikan antara $\operatorname{Harga}\left(\mathrm{X}_{1}\right)$ dengan Kualitas Pelauyanan $\left(\mathrm{X}_{2}\right)$. Hal ini ditunjukan dengan besaran koefiseun jalur $\left(\mathrm{P}_{21}\right)$ sebesar 0.238 lebih dari 0.05. Pengaruh positif dan signifikan tersebut artinya, jika harganaik maka kualitas pelayanan ikut naik.

b. Hipotesis Kedua,secara teoritik menduga bahwa Harga mempengaruhi Promosi. Hasil pengujian yang diperoleh bahwa terdapat pengaruh secara positif dan signifikan antara $\operatorname{Harga}\left(\mathrm{X}_{1}\right)$ dengan Promosi $\left(\mathrm{X}_{3}\right)$. Hal ini ditunjukan dengan besaran koefiseun jalur $\left(\mathrm{P}_{31}\right)$ sebesar 0.375lebih dari 0.05. Pengaruh positif dan signifikan tersebut artinya, jika harga naik maka budaya promosi naik. 
c. Hipotesis Ketiga,secara teoritik menduga bahwa Harga mempengaruhi Minat Masyarakat. Hasil pengujian yang diperoleh bahwa terdapat pengaruh langsung secara positif dan signifikan antara Harga $\left(\mathrm{X}_{1}\right)$ dengan Minat Masyarakat (Y). Hal ini ditunjukan dengan besaran koefiseun jalur $\left(\mathrm{P}_{32}\right)$ sebesar 0.303lebih dari 0.05 . Pengaruh langsung secara positif dan signifikan tersebut artinya, jika harga naik maka minat masyarakat naik.

d. Hipotesis Keempat, secara teoritik menduga bahwa Kualitas Pelayanan mempengaruhi Promosi.Hasil pengujian yang diperoleh bahwa terdapat pengaruh secara positif dan signifikan antara Kualitas pelayanan $\left(\mathrm{X}_{2}\right)$ dengan Promosi $\left(\mathrm{X}_{3}\right)$. Hal ini ditunjukan dengan besaran koefiseun jalur $\left(\mathrm{P}_{41}\right)$ sebesar 0.191lebih dari 0.05. Pengaruh secarapositif dan signifikan tersebut artinya, jika kualitas pelayanan naik promosi ikut naik.

e. Hipotesis Kelima, secara teoritik menduga bahwa Kualitas pelayanan mempengaruhi Minat masyarakat.Hasil pengujian yang diperoleh bahwa terdapat pengaruh secara positif dan signifikan antara Kualitas Pelayanan $\left(\mathrm{X}_{2}\right)$ dengan Minat Masyarakat $\left(\mathrm{X}_{4}\right)$. Hal ini ditunjukan dengan besaran koefiseun jalur $\left(\mathrm{P}_{42}\right)$ sebesar 0.142lebih dari 0.05. Pengaruh secarapositif dan signifikan tersebut artinya, jika kualitas pelayanan naik maka minat masyarakat ikut naik.

f. Hipotesis Keenam,secara teoritik menduga bahwa promosimempengaruhi minat masyarakat.Hasil pengujian yang diperoleh bahwa terdapat pengaruh secara positif dan signifikan antara promosi $\left(\mathrm{X}_{3}\right)$ dengan Minat masyarakat $\left(\mathrm{X}_{4}\right)$. Hal ini ditunjukan dengan besaran koefiseun jalur $\left(\mathrm{P}_{43}\right)$ sebesar 0.620lebih dari 0.05. Pengaruh secara positif dan signifikan tersebut artinya, jika promosi naik maka minat masyarakat ikut naik.

\section{DAFTAR PUSTAKA}

Adiwarman Azwar Karim. 2006. Sejarah Pemikiran Ehonomt Islam. Jakarta: Rajawali Press Edisi Ketiga.
Bernard H. W. 1970. Mentai Health in The Classroom. New York : Mc Graw-Hill.

Indriyo, Gitosudarmo. 2012. Manajemen Pemasaran Edisi2. Yogyakarta : BPFP-Yogyakarta.

Kasim, Anwar. 2000. Bimbingan Konseling. Universitas Terbuka.

Mahmud, Machfoedz. 2010. Komunikasi Pemasaran Moderen. Yogyakarta: Cakra Ilmu. Bumi Aksara.

Mohammad Hidayat, 2010. An Introduction To The Sharia Economic. Jakarta: Zikrul Hakim.

Nadia Hanum Amiruddin 2013. Price, Service Quality and Customer Loyalty: A Case of Air Asia. South East Asia Journal of Contemporary Business, Economic and Law, Vol. 2 Issue 1 (June) ISSN 2289-1560.

Philip Kotler dan Gary Amstrong. 2012. Marketing Manajemen Edisi 14 England: Pearson Education Linmited.

Philip Kotler dan Gary Amstrong. 2008. Prinsip-Prinsip Pemasaran Edisi 12 JILID1 (alih bahasa: Bob Sabran). Jakarta: Erlangga.

Philip Kotler dan Gary Amstrong. 2008. Prinsip-Prinsip Pemasaran Edisi 12, jilid 1.

Rambat, Lupiyoadi dan A. Hamdani. 2011. Manajemen Pemasaran Jasa edisi 2. Jakarta: Salemba Empat

Ronald. J Ebert dan Ricky W Griffin. 2007. Bisnis Edisi Kedelapan Jilid I (Terjemahan Sita Wardhani). Jakarta: Erlanga.

Setiawan, Yasin, 2008. Pengembangan Minat Menulis Anak',

http://www.geocities

Sopjan, Assauri. 2010, Manajemen Pemasaran, Jakarta: Raja Grafindo.

Sujanto, Sandjaja. 2008. Pengaruh Keterlibatan Orang Tua Terhadap Minat Membaca anak ditinjau dari Pendekatan Stress Lingkungan.

http://wordprees.com.2008/04/19mǐnat

Walter V, Bingham. 1949. Apttitudes and Apttitude Testing. New York: Harper 